\title{
LA RESPONSABILIDAD SOCIAL DE LA EMPRESA Y SU INTERRELACIÓN CON EL DERECHO DEL TRABAJO
}

\author{
LUCIANA ABOIM MACHADO GONÇALVES DA SILVA* \\ Universidad Federal de Sergipe, Brasil
}

La responsabilidad social de la empresa es un tema que está en pauta en diversas naciones, habiendo surgido por primera vez en Europa y hoy alcanzando prácticamente todas las naciones como un proceso de expansión democrática.

Aunque la definición de responsabilidad social esté en construcción, podemos decir que la responsabilidad social de la empresa se presenta en una forma filosófica de gestión en que la empresa asume una posición de corresponsabilidad en el desarrollo económico-social sustentable, proporcionando calidad de vida a sus empleados y familiares, a la comunidad local y a la sociedad como un todo.

La responsabilidad social corporativa tiene su raíz en la nueva visión que se atribuye a la definición de propiedad. Haciendo un análisis histórico, percibimos que la propiedad, al principio, era vista desde una perspectiva individualista, concediendo libertad plena al titular del bien, bajo la protección del Estado Liberal ${ }^{1}$.

Sin embargo, los tiempos han cambiado. Desde el siglo XX, debido a la aproximación del derecho a la moral y a la justicia, se atribuyó un nuevo sentido a la propiedad, con vistas al equilibrio de la libertad con la justicia social.

Sobre ese tema, Konrad Hesse ${ }^{2}$ enseña que el derecho privado ha dejado de atender solamente la autodeterminación individual y ha pasado también a preocuparse por la justicia social. Como consecuencia de eso, se reconoció en el ámbito jurídico, de forma expresa, el principio de la función social de la propiedad ${ }^{3}$ que, en el caso brasileño, vino con la

\footnotetext{
Doctora en Derecho del Trabajo por la Facultad de Derecho de la Universidad de San Pablo-USP. Máster en Derecho Laboral, Especialista en Derecho Laboral y en Derecho Procesal Civil, títulos obtenidos en la Pontificia Universidad Católica de San Pablo - PUC/SP. Curso de Postgrado en Derecho del Trabajo - "Descentralización productiva y dependencia laboral" - por la Universidad de Buenos Aires - U.B.A. Profesora Adjunta en grado y postgrado del Departamento de Derecho de la Universidad Federal de Sergipe- UFS. Vicecoordinadora del Programa de Máster en Derecho de la Universidad Federal de Sergipe. Investigadora del Consejo Nacional de Desarrollo Científico y Tecnológico - CNPq. Investigadora y Miembro de la Cámara de Asesoramiento de la Fundación de Apoyo a la Investigación y a la Innovación Tecnológica del Estado de Sergipe - FAPITEC/SE. Miembro de la Asociación Iberoamericana de Derecho del Trabajo y de la Seguridad Social. Miembro y Coordinadora del Comité Seccional de Nordeste de Brasil del Instituto Latinoamericano de Derecho del Trabajo y de la Seguridad Social.

1 Se subraya que la Constitución Imperial de Brasil de 1824 aseguraba, en el artículo 179, el "derecho de propiedad en toda su plenitud". Ya la Constitución Brasileña de 1891 preveía que "el derecho de propiedad se mantiene en toda su plenitud, excepto la expropiación por necesidad o utilidad pública, mediante previa indemnización” (art. 72, $\$ 17$ ).

2 Hesse, Konrad. Derecho Constitucional y Derecho Privado. Tradução de Ignacio Gutiérrez. Madrid: Editorial Civitas, 1995, p. 74.

3 El primer diploma legislativo a tratar de la función social de la propiedad fue la Constitución de Weimar (Alemana), que en su artículo 153 dispuso: "La Constitución garantiza la propiedad. Su contenido y sus límites resultan de la ley (...). La propiedad obliga y su uso y ejercicio deben al mismo tiempo representar una función en el interés social". MARTINS-COSTA, Judith (org.). A reconstrução do direito privado. São Paulo: Revista dos Tribunais, 2002, p. 796.
} 
primera Constitución Social, de $1934^{4}$, al condicionar el ejercicio de la propiedad con el interés social, orientación esta que se mantuvo en las Constituciones siguientes, incluso en la actual, de 1988.

La Constitución brasileña de 1988 establece, entre los derechos y garantías fundamentales, en el artículo $5^{\circ}$, inciso XXIII, que "la propiedad cumplirá con su función social" y dispone también, en el artículo 170, que "el orden económico, fundado en la valoración del trabajo humano y en la libre iniciativa, tiene como fin asegurar a todos existencia digna, de acuerdo con los dictámenes de la justicia social", observando, entre otros, el principio de la función social de la propiedad.

De esa manera, el principio de la función social de la propiedad, cuya consecuencia es la función social de la empresa, condiciona el ejercicio de la actividad empresarial a la justicia social.

Por lo tanto, la libertad de iniciativa empresarial tiene que ser ejercitada no solo con vistas al lucro, sino también como instrumento de justicia social ${ }^{5}$, proporcionando una mejor distribución de renta con la debida valoración del trabajo humano ${ }^{6}$.

Desde esa perspectiva, Celso Antonio Bandeira de $\mathrm{Melo}^{7}$ enseña que la función social es un medio para exigir el compromiso de la empresa con "el proyecto de una sociedad más igualitaria o menos desequilibrada -como es el caso de Brasil- en la cual, el acceso a la propiedad y su uso se orienten a proporcionar mayores oportunidades a todos los ciudadanos independientemente de la utilización productiva que tenga esta propiedad".

Con esa misma visión, Pietro Perlingieri ${ }^{8}$ afirma que la acción comunitaria originada de la función social:

\footnotetext{
4 La Constitución de 1934 establecía que estaba "garantizado el derecho de propiedad", que no podría "ser ejercido contra el interés social o colectivo, en la forma que determine la ley" (art. $113, \$ 17$ ). Sobre eso, Orlando Gomes comenta que el relator general del anteproyecto de la Constitución de 1934 ya defendía la utilización del término "función social", aunque este no haya sido adoptado, eligiéndose la expresión "interés social". Ya la Constitución de 1946 establecía, en el art. 147, que "el uso de la propiedad será condicionado al bienestar social”. La Constitución de 1967, con la Enmienda de 1969, utilizó, por primera vez -en el art. 160, inciso III- la expresión "función social" de la propiedad, previendo como un principio en la parte relativa al orden económico, en los siguientes términos: "El orden económico y social tiene como fin realizar el desarrollo nacional y la justicia social, con base en los siguientes principios: (...) III- función social de la propiedad". GoMES, Orlando. Direitos Reais $-10^{\text {a }}$ ed.-. Río de Janeiro: Forense, 1990, p. 101.

5 Es importante subrayar que, aunque el enlace entre la actuación empresarial y la justicia social es considerado una perspectiva hodierna, el "Derecho del Trabajo", desde su origen, adopta esa forma de pensar, habiendo sido incluso denominado como "Derecho Social" por algunos autores, a ejemplo del jurista brasileño Cesarino Júnior. A ese respecto, es oportuno registrar las lecciones de ese autor: “¿No es válido actualmente el concepto de que la propiedad tiene función social? ¿Por qué aceptar este hecho en varios aspectos de la propiedad privada y negarlo en cuanto a la propiedad de la empresa? No se puede olvidar que la empresa hoy tiene la función casi pública, lo que justifica que la propiedad esté también sometida a restricciones como ocurre con la propiedad inmobiliaria y, en varios casos, incluso la mobiliaria." CESARINO JUNIOR, A. F. Direito Social Brasileiro, vol. II. 6a ed., São Paulo: Saraiva, 1970, p. 13.

6 El texto constitucional brasileño, aun, expresa, en el art. 186, que la función social se cumple cuando la propiedad rural atiende, simultáneamente, entre otros, al requisito de la explotación que favorece el bienestar de los propietarios y de los trabajadores.

7 Bandeira De Melo, Celso Antônio. "Novos aspectos da Função Social da Propriedade no Direito Público", en: Revista de Direito Público-RDP-, vol. 20, no. 84, out./dez, 1987, p. 44.

8 PerlingIerI, Pietro. O Direito Civil na legalidade constitucional. Tradução de Maria Cristina de Cicco. Río de Janeiro: Renovar, 2008, pp. 943-944.
} 
"exige que la relación propietaria sea permeada por la justicia, esto es, que garantice la protección de los no propietarios no solo por la reglamentación de los poderes propietarios, sino también por medio de una disciplina distributiva que favorezca la participación de los no propietarios en la gestión de los bienes, o sea, el acceso a los mismos".

Hay que registrar, sin embargo, que la función social no tiene la finalidad de aniquilar las libertades de los empresarios, pero sí la de introducir la solidaridad social en la actividad económica, y de establecer límites al ejercicio de la autonomía de la voluntad, cuya importancia se acentúa en países como Brasil, donde la pobreza y la miseria impiden que parte sustancial de la sociedad tenga el legítimo derecho a la autonomía.

La previsión normativa de la función social de la propiedad no es meramente retórica y sin ninguna consecuencia concreta; constituye, como explica Fábio Konder Comparato ${ }^{9}$, un "poder-deber del propietario de dar a la cosa una destinación compatible con el interés de la colectividad", transmutándose cuando los bienes son incorporados a una explotación empresarial en "poder-deber del titular del control de dirigir la empresa para la realización de los intereses colectivos".

Así, la empresa es una institución cuya importancia trasciende la esfera económica, considerando que abarca intereses sociales, como la propia sobrevivencia digna y el bienestar de sus empleados y de los demás ciudadanos que de ella dependen o con ella comparten el mismo espacio social.

En otras palabras, esa previsión normativa de la Constitución brasileña de 1988 conduce a la interpretación de que el poder directivo del empleador constituye un "derechofunción". El empleador detiene el derecho de su propiedad, no solo para actuar en defensa de su propio interés, sino también y principalmente en función del interés social, que abarca los intereses de los trabajadores y de la comunidad.

De esa misma forma, al legitimar la responsabilidad social de la empresa en el ámbito laboral, la Ley Brasileña de Sociedades Anónimas (Ley n 6.404/76, art. 154, \$4º) prevé: "el consejo de administración o los directivos pueden autorizar la práctica de actos gratuitos razonables en beneficio de los empleados o de la comunidad en la que participa la empresa, considerando sus responsabilidades sociales" 10 .

Igualmente, en el ámbito internacional, la Organización Internacional del Trabajo (OIT), defiende la consolidación del trabajo decente, con el objetivo de evitar, o -al menos minimizar- la explotación del hombre, ícono del inicio de la industrialización y que parece retomar el aliento en el reciente neoliberalismo predatorio.

9 Comparato, Fábio Konder. Direito Empresarial: estudos e pareceres. São Paulo: Saraiva, 1995, p. 34.

10 Las cursivas son nuestras. 
Define el trabajo decente como "trabajo productivo y adecuadamente remunerado, ejercido en condiciones de libertad, equidad y seguridad, sin ninguna forma de discriminación, y capaz de garantizar una vida digna a todas las personas que viven de su trabajo"11.

Por lo tanto, la responsabilidad social de la empresa aplicada a las relaciones del trabajo tiene soporte en las normas internacionales y nacionales, constituyendo factor determinante en el comportamiento del empleador y fuente de estímulo y sanciones a determinadas conductas.

Dentro de ese contexto, el empleador no puede eximirse de la responsabilidad social hacia sus empleados, que va mucho más allá del cumplimiento de las obligaciones previstas en el contrato de trabajo, debiendo incorporar el cambio de mentalidad para atender el lado de los intereses directos de la empresa, los intereses de los trabajadores y de la comunidad.

Uno de los caminos elegidos para la eficacia social de las citadas normas jurídicas fue la legitimación de iniciativas voluntarias de la empresa, o sea, la idea de responsabilidad social ("social responsability" o "business conscience") que está asociada a un compromiso consciente y personal en materias sociales, a partir de acciones voluntarias y filantrópicas de la empresa ("corporate altruism").

A ese respecto, Patrícia Ashley ${ }^{12}$ destaca que la empresa, a través de la responsabilidad social, asume obligaciones de carácter moral, además de aquellas establecidas en ley. Tales obligaciones no son necesariamente vinculadas a su actividad, pero pueden contribuir con el desarrollo sustentable de la comunidad, interfiriendo en la mejoría de la calidad de vida de la sociedad.

La responsabilidad social de las empresas suele dividirse en dos aspectos: interno y externo; el primero consiste en la preocupación por las condiciones de trabajo, calidad de empleo, remuneraciones y medio ambiente del trabajo, ya el segundo se plasma en la atención de la empresa hacia la comunidad en que está insertada.

A modo de ejemplo, se destacan como beneficios sociales voluntarios para los empleados la asistencia para vivienda, pensiones, beneficios por muerte, la recolocación en el mercado del trabajo para empleados despedidos, etc.; ya como beneficios para la comunidad se destacan las donaciones a instituciones de investigación, educación y actividades filantrópicas.

Con eso se quiere decir que tal comportamiento altruista de la empresa, bajo la perspectiva de la responsabilidad social, no puede ser exigido por el Derecho como una obligación legal (contraprestación pecuniaria del trabajo), caracterizándose, por lo tanto, por la espontaneidad. Esto es, el Derecho actúa, en esta hipótesis, solo con el fin de legitimar o estimular las conductas voluntarias, pero no con el fin de obligar algún tipo de acción.

\footnotetext{
11 Los cuatro ejes centrales de la Agenda del Trabajo Decente son la creación de empleo de calidad para hombres y mujeres, la extensión de la protección social, la promoción y el fortalecimiento del diálogo social y el respeto de los principios y derechos fundamentales en el trabajo, expresos en la "Declaración de los Derechos y Principios Fundamentales en el Trabajo" (1998) de la OIT, que son: libertad de asociación, eliminación de todas formas de trabajo forzado u obligatorio, abolición efectiva del trabajo infantil y eliminación de la discriminación en materia de empleo y ocupación. (Disponible en: http://www.oitbrasil.org. br)

12 ASHLEY, Patrícia. Ética e responsabilidade social nos negocios. São Paulo: Saraiva, 2003, p. 7.
} 
El argumento común encontrado por la doctrina para justificar tales acciones es que las donaciones caritativas realizadas por la empresa pueden ser consideradas gastos de propaganda o gastos de relaciones públicas. Por eso con frecuencia las empresas divulgan sus acciones rotuladas con la nomenclatura de "balance social", a fin de obtener una "imagen positiva".

Eso porque no es solo el aporte financiero que determina el crecimiento empresarial, sino también el interés de la sociedad en el éxito de la actividad empresarial.

En otras palabras, las empresas son gradualmente obligadas a divulgar su desempeño social y ambiental, mostrando el impacto de sus actividades y las medidas tomadas en la prevención o la compensación de daños sociales. En ese sentido, empresas publican informes anuales, a través de los cuales se evalúa su desempeño según las más diferentes modalidades, incluso en el campo de las relaciones de trabajo.

En el ámbito laboral, es importante recordar que, buscando crear barreras a los productos producidos sin respetar los derechos humanos de los trabajadores, se crearon las "cláusulas sociales", medidas "antidumping" relacionadas al trabajo y a los derechos humanos, las cuales son utilizadas en negociaciones comerciales para vetar la compra de productos producidos por países que no promuevan condiciones dignas de trabajo.

Eso porque las empresas que no respetan los derechos laborales, por regla general, ofertan productos o servicios con precios más competitivos y, por lo tanto, presentan mayor índice de exportación, generando una competencia desleal en el mercado globalizado.

La adopción de cláusulas sociales representa un importante mecanismo de implementación de la responsabilidad social corporativa. Con ese objetivo, hay un programa denominado "Empresa Amiga del Niño", de la Fundación Abrinq, que defiende la introducción de cláusulas sociales como forma de erradicar el trabajo infantil. Para eso, uno de los compromisos que una empresa tiene que cumplir para convertirse en una "Empresa Amiga del Niño", es alertar a sus proveedores, por medio de cláusula contractual u otros instrumentos, que una denuncia comprobada de trabajo infantil puede causar la ruptura de la relación comercial. Por lo tanto, ese programa se preocupa por las condiciones sociales en las que los insumos adquiridos fueron fabricados, reconociendo, por medio de un sello social, las empresas comprometidas con la infancia y adolescencia en Brasil.

Así, con la creciente presión por transparencia en los negocios, las empresas se ven forzadas a adoptar una postura ética y más responsable en sus acciones, buscando, paralelamente, el bienestar social, y, principalmente, un mejor desempeño en los negocios $\mathrm{y}$, consecuentemente, mayor rentabilidad.

Es importante resaltar que las iniciativas empresariales, fundamentadas en su responsabilidad social, suelen ser adoptadas por empresas con mayor poder de mercado ${ }^{13}$, dado que, desde el punto de vista económico, cuanto menor es una empresa, o cuanto más opera en condiciones competitivas, más justificado está que actúe solamente cumpliendo las obligaciones legales y con base en las fuerzas de mercado.

13 El compromiso de la empresa en acciones voluntarias con vistas a su responsabilidad social debe guardar proporcionalidad con su aporte financiero. Luego, es inviable el cumplimiento de la responsabilidad social corporativa cuando el emprendimiento pasa por dificultades financieras. 
La responsabilidad social corporativa está diseminándose, más y más, en la práctica empresarial brasileña. Con el objetivo de incentivar a la empresa a destinar recursos razonables a las causas públicas, humanitarias, educacionales y filantrópicas, BOVESPA (Bolsa de Valores de San Pablo) creó el Índice de Sustentabilidad Empresarial (ISE), el cual "tiene por objetivo reflejar en la rentabilidad de una cartera compuesta por acciones de empresas reconocidamente comprometidas con la responsabilidad social y la sostenibilidad empresarial, y también actuar como promotor de buenas prácticas en el medio empresarial brasileño" 14 .

Siguiendo por ese camino, es común, también, la filiación de empresas a entidades no gubernamentales que patrocinan la responsabilidad social. Ese es el caso de SAI (Social Accountability International). Se trata de una organización internacional no gubernamental de derechos humanos y sin ánimos lucrativos dedicada al trato ético de los trabajadores alrededor del mundo que elaboró la norma SA 8000, con el fin de conceder un certificado social a las empresas que respeten a esta norma.

La SA8000 es una norma basada en Convenciones de la OIT (Organización Internacional del Trabajo), en la Convención de las Naciones Unidas sobre los Derechos del Niño y en la Declaración Universal de los Derechos Humanos. La norma abarca nueve temas: Trabajo Infantil, Trabajo Forzado, Seguridad y Salud en el trabajo, Libertad de asociación y Derecho de negociación colectiva, Discriminación, Prácticas disciplinares, Jornada laboral, Remuneración y Sistemas de gestión ${ }^{15}$.

No obstante, el empleador socialmente responsable necesita, en primer lugar, valorar a sus empleados, dejando en segundo plano la preocupación por la divulgación al público externo de acciones socialmente responsables.

A ese respecto, se registran las lecciones de Pedro Washington de Almeida ${ }^{16}$ :

"En la construcción de una imagen que sea políticamente correcta junto a los clientes, proveedores y sociedad en general, las empresas no pueden olvidarse de la parte "de dentro" -funcionarios, sus familias, franquiciadores, 'trainees', entre otros- bajo pena de crear políticas y prácticas esquizofrénicas y excluyentes. Así, la decisión de construir una guardería-modelo en la villa "Perro Loco" o una fantástica Escuela Profesional en la que el criterio de ingreso es no ser hijo de funcionario, ciertamente será mal comprendida por obreros cuyos salarios impiden el sueño de una vida mejor para sus hijos".

A la par de esa responsabilidad social corporativa voluntaria, está la función social de la empresa oriunda de la imposición legal, como consecuencia de las ideas de relaciones sociales más justas, de igualdad real, de aumento y distribución más equitativa de riqueza, que corroboran la función social de la empresa y llevan a comprender que la libre iniciativa

\footnotetext{
14 Disponible en: http://www.bovespa.com.br

15 Disponible en: http://www.sa-intl.org

16 ALMEIDA, Pedro Washington de. $1^{\circ}$ Anuário de responsabilidade social-Paraná: iniciativas que apontam soluçōes para ofuturo. Curitiba: Paranapress, 2003, pp. 18-19.
} 
no será legítima mientras se ejerza con el objetivo exclusivo de lucro, pero lo será mientras propicien la justicia social, la implementación de la igualdad de oportunidades y la humanización de las relaciones sociales.

Ejemplo de eso, en las relaciones de trabajo, es el cumplimiento de la ley brasileña -Ley no 8.213/91 (art. 93, caput)- que obliga las empresas con 100 o más empleados a completar entre el $2 \%$ (dos por ciento) y $5 \%$ (cinco por ciento) de sus cargos con beneficiarios rehabilitados o personas discapacitadas. Se destaca, también, a título de ilustración, las acciones afirmativas promovidas por el Ministerio Público del Trabajo, exigiendo la contratación, por parte de las empresas, de personas de determinada raza, buscando su inclusión social.

De lo expuesto, se infiere la existencia de mecanismos voluntarios y coercitivos de implementación de la función social de la empresa. Es por eso que Detlef Krause ${ }^{17}$ distingue social responsability, marcada por la voluntariedad, de la social accountability, que obliga la empresa a cumplir ciertos dictámenes legales reguladores de las relaciones sociales.

Es cierto que son incontables las dificultades para concretar la responsabilidad social corporativa bajo el sesgo coercitivo (social accountability), prevista en disposiciones legales y jurisprudencias direccionadas hacia la implementación de la justicia social en las relaciones laborales, una vez que no se refieren a la distribución de beneficios por el Estado, sino a los resultados de una actividad privada.

Por otro lado, se sabe que la imposición de gravámenes a la actividad empresarial es normalmente contabilizada en los precios finales de los productos y servicios, de modo que la sociedad sufre las consecuencias de esa implementación coercitiva, consecuente de la función social de la empresa, principalmente cuando se trata de actividades desarrolladas en mercados poco competitivos.

Sin embargo, tales trabas no pueden desalentar la valoración de la responsabilidad social de la empresa, a través de las acciones que proporcionan la distribución de riquezas de forma sustentable y "la construcción de una sociedad libre, justa y solidaria" (Constitución brasileña de 1988 , art. $\left.3^{\circ}, \mathrm{I}\right)$.

La actuación del hombre, incluso en la gestión de una empresa, debe dirigirse hacia la práctica del bien común; como dice Blaise Pascal, "el hombre está hecho visiblemente para pensar, es toda su dignidad y todo su mérito; y todo su deber es pensar bien".

\section{BIBLIOGRAFÍA}

AlmeIDA, Pedro Washington de. $1^{\circ}$ Anuário de responsabilidade social-Paraná: iniciativas que apontam soluçöes para o futuro. Curitiba: Paranapress, 2003.

ASHLEY, Patrícia. Ética e responsabilidade social nos negócios. São Paulo: Saraiva, 2003.

Bandeira de MElo, Celso Antônio. "Novos aspectos da Função Social da Propriedade no Direito Público", en: Revista de Direito Público-RDP-, vol. 20, nº. 84, out./dez, 1987.

Cesarino Junior, A. F. Direito Social Brasileiro, vol. II. -6a ed.-. São Paulo: Saraiva, 1970.

17 Krause, Detlef. "Corporate Social Responsibility: Interests and Goals", en: HOPT, Klaus J.; TeUBnER, Gunther (org.). Corporate Governance and Directors Liabilities. Legal, Economic and Sociological Analyses on Corporate Social Responsibility. Berlin/New York: Walter de Gruyter, 1985, p. 97. 
Comparato, Fábio Konder. Direito Empresarial: estudos e pareceres. São Paulo: Saraiva, 1995.

GOMES, Orlando. Direitos Reais -10ª ed.-. Río de Janeiro: Forense, 1990.

HESSE, Konrad. Derecho Constitucional y Derecho Privado. Tradução de Ignacio Gutiérrez. Madrid: Editorial Civitas, 1995.

KRAUSE, Detlef, "Corporate Social Responsibility: Interests and Goals", en: HOPT, Klaus J.; TEUBNER, Gunther (org.). Corporate Governance and Directors Liabilities. Legal, Economic and Sociological Analyses on Corporate Social Responsibility. Berlin/New York: Walter de Gruyter, 1985.

LiMA, Paulo Rogério dos Santos. "Balanço social: ferramenta de gestão e informaçăo. Intergraçăo", en:•A revista eletrônica do terceiro setor, $\mathrm{n}^{\circ} .6$, set., 2001. Disponível em: http://200.224.250.199/banco.htm .

MARTINS-COSTA, Judith (org.). A reconstrução do direito privado. São Paulo: Revista dos Tribunais, 2002.

PerlingIeRI, Pietro. O Direito Civil na legalidade constitucional. Traduçáo de Maria Cristina de Cicco. Río de Janeiro: Renovar, 2008.

TOMEI, Patrícia A. "Responsabilidade social de empresas: análise qualitativa da opinião do empresariado nacional", en: Revista de Administração de Empresas, Fundação Getúlio Vargas, Río de Janeiro, vol. 24, nº. 4, pp. 189-202, out. /dez., 1984.

VAZ, Isabel. Direito econômico das propriedades. -2. ed.-. Río de Janeiro: Forense, 1993.

Vergara, Sylvia Constant; Branco, Paulo Durval. "Empresa humanizada: a organização necessária e possível", en: Revista de Administração de Empresas, São Paulo, vol. 41, nº. 2, pp. 20-30, ago. /jun., 2001. 